\title{
Faecal microbiota transplantation as an elixir of youth
}

\author{
Craig Haifer ${ }^{1,2}$, Sudarshan Paramsothy ${ }^{2}$, Rupert W. Leong ${ }^{1,2,3}$ \\ ${ }^{1}$ Concord Clinical School, The University of Sydney, Sydney, Australia; ${ }^{2}$ Gastroenterology and Liver Services, Concord Repatriation General \\ Hospital, Sydney, Australia; ${ }^{3}$ South Western Clinical School, UNSW, Sydney, Australia \\ Correspondence to: Rupert W. Leong. Concord Repatriation General Hospital, Hospital Road, Concord NSW 2139, Australia. \\ Email: rupertleong@outlook.com. \\ Provenance and Peer Review: This article was commissioned by the editorial office, Hepatobiliary Surgery and Nutrition. The article did not undergo \\ external peer review. \\ Comment on: Bárcena C, Valdés-Mas R, Mayoral P, et al. Healthspan and lifespan extension by fecal microbiota transplantation into progeroid mice. \\ Nat Med 2019;25:1234-42.
}

Submitted Oct 28, 2019. Accepted for publication Nov 25, 2019.

doi: $10.21037 /$ hbsn.2019.11.17

View this article at: http://dx.doi.org/10.21037/hbsn.2019.11.17

The intestinal microbiota has been increasingly seen to be responsible for various gastrointestinal disorders such as inflammatory bowel diseases (1). However, their effects on systemic physiological processes unrelated to the intestinal tract are of increasing interest. In this issue of Nature Medicine, Bárcena et al. investigated whether intestinal microbiota might influence aging (2). Using 16S RNA and metagenomic sequencing on mouse models and humans with progeroid syndrome compared to healthy centenarian controls with a prolonged lifespan, the authors identified that a loss of Akkermansia muciniphila and Debalobacterium and enrichment of Parabacteroides and Prevotella spps to be significantly associated with the aging process. There was consistency of the two cohorts in terms of differences in microbial composition with suppressed or enriched species.

The consistency between human cohorts and mouse models allowed for further interventional research on the animal model. To prove causality rather than simply association, faecal microbiota transplantation (FMT) was performed using wild type control mice as donors to the progeria mouse model. FMT refers to the transfer of intestinal organisms from healthy donor to a disease recipient in order to reverse intestinal dysbiosis. Mice recipients of FMT showed delayed loss of body weight and temperature, avoided hypoglycaemia and renal perivascular fibrosis, and had improved intestinal inflammation markers, which are biomarkers of the progeroid disease phenotype. Importantly, progeria mouse who received FMT had improved survival versus control (160 vs. 140 days,
$\mathrm{P}=0.0029)$. Separately, progeria mice supplemented with $A$. Muciniphilia also showed modest life span extension when compared with controls. Lifespan extension was associated with enrichment of secondary bile acid synthesis and other metabolites, demonstrating how a changing intestinal microbiome may alter the underlying physiology through shifts in metabolic pathways.

Dysbiosis and subsequent changes in metabolic pathways might be responsible systemic processes such as aging. FMT seems effective in "correcting" the dysbiosis found in progeria mice and the study begs the question whether advancing this research further might yield an 'elixir of youth', that is, bacterial products that when enriched, results in an anti-aging therapy. The impact of this study is, therefore, potentially astronomical. Enrichment of Prevotella species in the intestinal microbiome has been consistently associated with elevated systemic inflammation and inflammatory conditions such as rheumatoid arthritis (3). Importantly, the presence of $A$. muciniphilia species reduced intestinal inflammation, improves gut-barrier integrity and decreased the development of obesity and diabetes (4-6). This link between A. Muciniphilia and health is not new. The species is especially prevalent in subjects that are fasting, as the organism prefers to receive its nutritional source from the mucus lining the intestinal tract than ingested food (7). Therefore, there are links between the present study with the known health benefits of intermittent and prolonged fasting, which enhances the proportion of A. Muciniphilia by reciprocal suppression of other intestinal 
microbial species that requires food.

The potential links between the microbial constituents and aging might be through confounding factors of concurrent disease, diet and lifestyle. The study demonstrated the association at different levels but the FMT data was limited to mice. Whether the intervention is an elixir of youth in humans remains speculative. Whether the magnitude of benefit from FMT is higher than through intermittent or prolonged fasting and indirectly through avoidance of obesity, also requires further research. Nevertheless, Bárcena and colleagues successfully highlighted microbial changes to be associated with differential aging phenotypes and demonstrated that the aging process may be manipulated.

\section{Acknowledgments}

Funding: None.

\section{Footnote}

Conflicts of Interest: All authors have completed the ICMJE uniform disclosure form (available at http://dx.doi. org/10.21037/hbsn.2019.11.17). Dr. CH reports grants from Ferring, other from Abbvie, personal fees and other from Takeda, other from Pfizer, outside the submitted work. Dr. SP reports he is a consultant for Finch Therapeutics, and has received speaker fees from Janssen and Ferring, outside the submitted work. Dr. RWL reports personal fees from $\mathrm{AbbVie}$, personal fees from Aspen, personal fees from Ferring, grants and personal fees from Hospira, grants and personal fees from Janssen, grants and personal fees from Takeda, grants from Shire, grants from NHMRC, personal fees from Celegene, personal fees from Dr. Falk Pharma, personal fees from Novartis, personal fees from MSD, outside the submitted work.

Ethical Statement: The authors are accountable for all aspects of the work in ensuring that questions related to the accuracy or integrity of any part of the work are appropriately investigated and resolved.

Open Access Statement: This is an Open Access article distributed in accordance with the Creative Commons Attribution-NonCommercial-NoDerivs 4.0 International License (CC BY-NC-ND 4.0), which permits the noncommercial replication and distribution of the article with the strict proviso that no changes or edits are made and the original work is properly cited (including links to both the formal publication through the relevant DOI and the license). See: https://creativecommons.org/licenses/by-nc-nd/4.0/.

\section{References}

1. Paramsothy S, Kamm MA, Kaakoush NO, et al. Multidonor intensive faecal microbiota transplantation for active ulcerative colitis: a randomised placebo-controlled trial. Lancet 2017;389:1218-28.

2. Bárcena C, Valdés-Mas R, Mayoral P, et al. Healthspan and lifespan extension by fecal microbiota transplantation into progeroid mice. Nat Med 2019;25:1234-42.

3. Alpizar-Rodriguez D, Lesker TR, Gronow A, et al. Prevotella copri in individuals at risk for rheumatoid arthritis. Ann Rheum Dis 2019;78:590-3.

4. Dao MC, Everard A, Aron-Wisnewsky J, et al. Akkermansia muciniphila and improved metabolic health during a dietary intervention in obesity: relationship with gut microbiome richness and ecology. Gut 2016;65:426-36.

5. Ottman N, Reunanen J, Meijerink M, et al. Pili-like proteins of Akkermansia muciniphila modulate host immune responses and gut barrier function. PLoS One 2017;12:e0173004.

6. Macchione IG, Lopetuso LR, Ianiro G, et al. Akkermansia muciniphila: key player in metabolic and gastrointestinal disorders. Eur Rev Med Pharmacol Sci 2019;23:8075-83.

7. Remely M, Hippe B, Geretschlaeger I, et al. Increased gut microbiota diversity and abundance of Faecalibacterium prausnitzii and Akkermansia after fasting: a pilot study. Wien Klin Wochenschr 2015;127:394-8.
Cite this article as: Haifer C, Paramsothy S, Leong RW. Faecal microbiota transplantation as an elixir of youth. HepatoBiliary Surg Nutr 2020;9(4):488-489. doi: 10.21037/ hbsn.2019.11.17 